\title{
Perbandingan Metode SOM/Kohonen dengan ART 2 pada Data Mining Perusahaan Retail
}

\author{
Anak Agung Gede Bagus Ariana ${ }^{1}$, I Ketut Gede Darma Putra ${ }^{2}$ Linawati $^{3}$
}

\begin{abstract}
This study investigates the performance of artificial neural network method on clustering method. Using UD. Fenny's customer profile in year 2009 data set with the Recency, Frequency and Monetary model data. Clustering methods were compared in this study is between the Self Organizing Map and Adaptive Resonance Theory 2. The performance evaluation method validation is measured by the index cluster validation. Validation index clusters are used, among others, Davies-Bouldin index, index and index Dunn Silhouette. The test results show the method Self Organizing Map is better to process the data clustering.
\end{abstract}

Index term- Data Mining, Artificial Neural Network, Self Organizing Map, Adaptive Resonance Theory 2.

Intisari-Penelitian ini ingin mengetahui unjuk kerja metode clustering data berbasis jaringan saraf tiruan. Menggunakan data set profil pelanggan UD. Fenny tahun 2009 dengan atribut Recency, Frequency dan Monetary. Metode clustering yang dibandingkan pada penelitian ini adalah Self Organizing Map dan Adaptive Resonance Theory 2. Evaluasi kinerja metode dilakukan dengan mengukur validasi index dari cluster yang terbentuk. Validasi cluster yang digunakan antara lain Indeks Davies-Bouldin, Indeks Dunn dan Indeks Silhouette. Hasil pengujian menunjukkan metode Self Organizing Map lebih baik dalam melakukan proses clustering data.

Kata Kunci- Data Mining, Jaringan Saraf Tiruan Self Organizing Map, Adaptive Resonance Theory 2.

\section{Pendahuluan}

Perusahaan ritel adalah perusahaan yang bergerak dalam bidang transaksi jual beli dalam jumlah kecil, satuan, atau eceran. Usaha ritel ini memiliki peranan penting dalam dunia perekonomian, karena tanpa usaha ritel suatu barang dari produsen tidak akan sampai di tangan konsumen. UD. Fenny merupakan perusahaan ritel yang menjual bahan kue, berlokasi di Jalan Nakula, Denpasar. Sejak tahun 2006 UD. Fenny telah menggunakan sistem informasi untuk menangani point of sales (POS) dan sistem inventory. Jumlah record transaksi ini bertambah secara signifikan dari tahun ke tahun. Jumlah record transaksi yang besar ternyata menyebabkan pihak manajemen sulit untuk menentukan keputusankeputusan bisnis yang terkait dengan masalah strategi

\footnotetext{
${ }^{1}$ Mahasiswa, Magister Teknik Elektro Universitas Udayana Gedung Pascasarjana Universitas Udayana Jl. PB Sudirman Denpasar-Bali 80232 (tlp/fax: 0361-239599; email: gungariana86@gmail.com)

2, ${ }^{3}$ Dosen, Magister Teknik Elektro Universitas Udayana, Gedung Pascasarjana Jl. PB Sudirman Denpasar-Bali 80232 (tlp/fax: 0361-239599; e-mail: duglaire@yahoo.com)
}

pemasaran. Akibatnya perusahaan sering kehilangan pelanggan yang potensial menjadi pelanggan loyal.

Untuk mengatasi permasalahan tersebut, dilakukan proses customer identification atau pengenalan pelanggan. Salah satu cara yang dilakukan adalah customer segmentation. Pelanggan dapat disegmentasi dengan mengacu pada beberapa atribut. Salah satu model atribut yang sering digunakan adalah model RFM (Recency, Frequency, dan Monetary). Recency merupakan waktu pembelian akhir dari pelanggan yang diukur dalam satuan hari, bulan maupun tahun. Frequency menggambarkan jumlah total jumlah transaksi pelanggan yang diukur dalam rentang waktu tertentu, dan monetary menggambarkan jumlah nilai yang dibelanjakan oleh pelanggan [1] [2] [3].

Penelitian Nugraheni [4] telah membandingkan dua metode Fuzzy yang digunakan untuk proses clustering data yaitu metode Fuzzy C-Means dan metode Fuzzy Substractive. Pemodelan data menggunakan model RFM. Evaluasi kinerja pembanding menggunakan metode Modified Partition Coefficient dan Partition Entropy. Hasil perbandingan menunjukkan metode Fuzzy C-Means menghasilkan cluster yang lebih baik daripada metode Fuzzy Subtractive.

Menurut Smita [5] pada penelitian mengenai potensi penggunaan jaringan saraf tiruan pada data mining, menyebutkan metode SOM/Kohonen, Neuro Fuzzy dan Adaptive Resonance Theory 2 sebagai metode yang memiliki kehandalan yang baik dalam melakukan proses clustering, namun belum dijelaskan secara spesifik perbandingan unjuk kerja ketiga metode tersebut.

Penelitian sebelumnya [6] oleh penulis telah berhasil membangun aplikasi data mining dengan mengunakan metode SOM/Kohonen dengan menggunakan data set yang sama. Pada penelitian ini belum dilakukan pembahasan mengenai unjuk kerja metode SOM/Kohonen. Model data yang digunakan pada penelitian ini adalah model RFM. Penelitian ini menekankan pada proses pembentukan data set, melalui tahapan pembangunan data warehouse yang siap untuk penelitian selanjutnya.

Penelitian sebelumnya [7] oleh penulis telah menerapkan penggunaan metode ART 2 untuk segmentasi pelanggan PDAM kabupaten Gianyar dengan menggunakan atribut data pemakaian air, golongan tarif PDAM dan diameter pipa. Pengukuran kualitas cluster menggunakan Indeks Validasi Silhouette. Mencapai nilai tertinggi mendekati 1 yaitu 0.95 , hal ini menunjukkan metode ART 2 baik untuk melakukan clustering data pelanggan PDAM.

Berdasarkan pemaparan diatas, dilakukan perbandingan kinerja metode SOM/Kohonen dan ART 2 dalam melakukan clustering data. Penilaian tingkat unjuk kerja metode dalam menentukan cluster terbaik diukur dengan menggunakan validasi cluster Indeks Davies-Bouldin, Indeks Dunn, dan 
Indeks Silhouette. Metode akan diuji dengan menggunakan data set profil pelanggan UD. Fenny tahun 2009.

\section{Self Organizing Map/KoHONEN}

Jaringan saraf tiruan SOM/Kohonen merupakan salah satu model jaringan saraf tiruan yang menggunakan metode unsupervised learning. Artinya, jaringan tersebut melakukan pembelajaran tanpa bimbingan data input-target [8].

Jaringan ini terdiri dari dua lapisan (layer), yaitu lapisan input dan lapisan output. Setiap neuron dalam lapisan input terhubung dengan setiap neuron pada lapisan output. Setiap neuron dalam lapisan output merepresentasikan cluster dari input yang diberikan. Adapun algoritma metode SOM/Kohonen adalah sebagai berikut:

0 . Neuron pada lapisan input (neuron input) sebanyak $n$ dinotasikan sebagai $x_{1}, x_{2}, \ldots, x_{n}$ dan neuron pada lapisan output (neuron output) sebanyak $m$ dinotasikan sebagai $y_{1}, y_{2}, \ldots, y m$. Bobot koneksi antara neuron input dan output dinotasikan sebagai $w_{i j}$ ditentukan secara acak antara 0 dan 1 .

1. Selama kondisi penghentian bernilai salah, lakukan langkah 2-7

2. Untuk setiap masukan $x$, lakukan langkah 3-5

3. Hitung semua $j$ dengan menggunakan persamaan (1)

$$
d_{j}=\sum_{i}\left(w_{j i}-x_{i}\right)^{2}
$$

4. Tentukan indeks $j$ sedemikian hingga $d_{(j)}$ minimum

5. Untuk setiap unit $j$ di sekitar $j$ modifikasi bobot dengan persamaan (2)

$$
w_{j i}^{b a r u}=w_{j i}^{\text {lama }}+\alpha\left(x_{i}-w_{j i}^{\text {lama }}\right)
$$

6. Modifikasi laju pemahaman

7. Uji kondisi penghentian dilakukan dengan menghitung selisih antara bobot baru dengan bobot lama, apabila nilai berubah tidak signifikan, berarti pengujian sudah mencapai konvergensi sehingga dapat dihentikan.

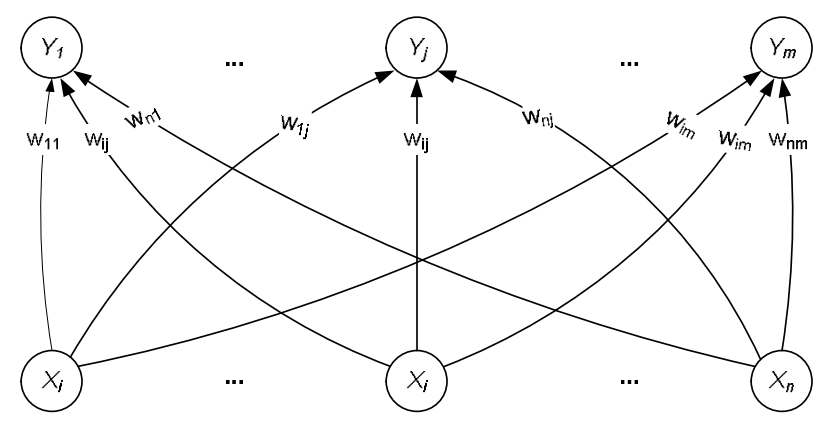

Gambar 1: Arsitektur Self-Organizing Map

\section{ADAPTIVE ReSOnANCE THEORY 2}

Adaptive Resonance Theory (ART) dirancang untuk mengatasi masalah kemampuan stabilitas-plastisitas (stabilityplasticity) untuk menyimpan informasi yang telah dipelajari ketika ada informasi baru yang dihadapi oleh jaringan saraf tiruan lainnya [9] [10]. Arsitektur dasar dari ART 2 terdiri dari tiga grup neuron yaitu: (1) Input processing field $-F_{1}$ layer yang mengombinasikan sinyal-sinyal dari bagian masukan dan lapisan $F_{2}$ yang nantinya digunakan dalam membandingkan kemiripan sinyal masukan dengan vektor bobot untuk unit cluster yang telah dipilih sebagai calon yang diperbolehkan untuk mempelajari pola masukan yang dimasukkan. (2) Cluster units $-F_{2}$ layer yang merupakan lapisan kompetitif, artinya unit cluster dengan jumlah masukan terbesar menjadi calon kuat yang diperbolehkan mempelajari pola masukan. (3) Reset mechanism. Suatu unit cluster diperbolehkan mempelajari pola masukan tergantung kepada kemiripan vektor top-down-nya dengan vektor masukan. Hal ini diatur oleh reset berdasarkan sinyal-sinyal yang diterimanya dari bagian masukan $F_{l}(a)$ dan bagian antarmuka $F_{l(b)}$ pada lapisan $F_{l}$. [11] [12] [13]

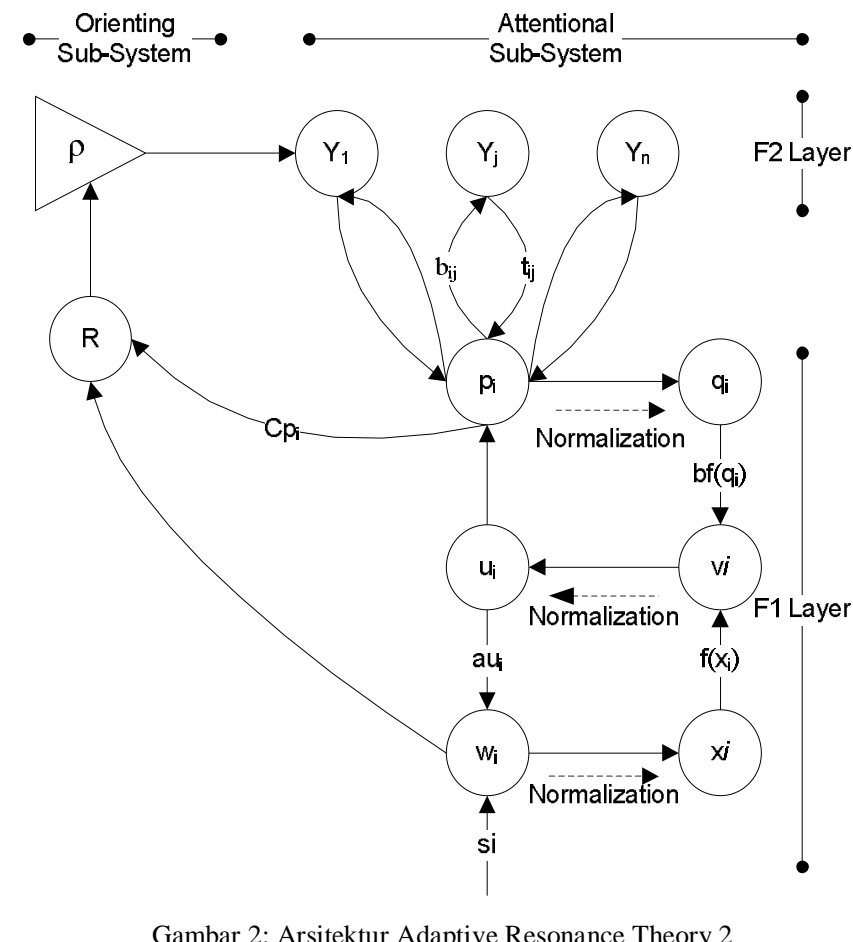

Dalam algoritma ART 2 pemilihan parameter harus dilakukan dengan baik karena merupakan komponen penting dalam menggunakan algoritma ART 2 baik tipe pembelajaran cepat atau tipe pembelajaran lambat. Parameter dalam algoritma ART 2 terdiri dari:

$n$ : Jumlah komponen inputan.

$a, b$ : Nilai tetap atau konstanta.

$c$ : Diinisialisasi sebagai 0,1 . Pemilihan nilai yang lebih kecil memberikan keefektifan terhadap nilai parameter vigilance.

$d$ : Aktivasi dari unit pemenang dalam layer $\mathrm{F}_{2}$, nilainya harus dipilih hampir mendekati 1 misalkan 0,9 karena akan memberikan keefektifan terhadap nilai parameter vigilance. 
Teknologi Elektro, Vol. 16, No. 02, Mei - Agustus 2017

$\theta$ : Noise suppression, nilai ini didapat menggunakan persamaan (3) dan fungsi ini berhubungan dengan fungsi aktivasi (4).

$$
f(x)= \begin{cases}x, & x \geq 0 \\ 0, & x<0\end{cases}
$$

$\alpha$ : Learning rate, atau laju pembelajaran.

$\rho$ : Vigilance factor atau derajat kewaspadaan. Nilai parameter ini dapat diset dari 0 sampai 1 namun pemberian nilai parameter kurang dari 0,7 adalah kurang efektif karena sama saja artinya dengan nilai 0

$b_{j}$ : Nilai bobot bottom-up dapat ditentukan dengan menggunakan persamaan (5).

$$
b_{j} \leq \frac{1}{(1-d) \sqrt{n}}
$$

$t_{j}$ : Inisialisasi nilai bobot top-down menggunakan nilai yang kecil sehingga dapat mencegah reset terjadi pada input pertama yang masuk dalam suatu cluster.

Berikut adalah algoritma pembelajaran ART 2:

0. Inisialisasi parameter $a, b, \theta, c, d, e, \alpha, p$.

1. Lakukan langkah 2-12 untuk setiap epoch training.

2. Untuk setiap masukan vektor $s$, lakukan langkah 3-11

3. Modifikasi unit aktivasi $F_{1}$

$$
\begin{array}{r}
u_{i}=0 \\
q_{i}=0 \\
p_{i}=0 \\
x_{i}=\frac{s_{i}}{e+\|\mathrm{s}\|} \\
w_{i}=s_{i} \\
v_{i}=f\left(x_{i}\right)
\end{array}
$$

Modifikasi unit aktivasi $F 1$ lagi.

$$
\begin{array}{r}
u_{i}=\frac{v_{i}}{e+\|\mathrm{v}\|} \\
w_{i}=s_{i}+a u_{i} \\
p_{i}=u_{i} \\
x_{i}=\frac{w_{i}}{e+\|\mathrm{w}\|} \\
q_{i}=\frac{p_{i}}{e+\|\mathrm{p}\|} \\
v=f\left(x_{i}\right)+b f\left(q_{i}\right)
\end{array}
$$

4. Hitung sinyal unit $F_{2}$

$$
y_{j}=\sum_{i} b_{i j} p_{i}
$$

5. Selama kondisi reset $=$ true lakukan langkah 6-7

6. Untuk unit $F_{2}$ pilih $Y_{j}$ dengan nilai paling besar.

7. Cek nilai reset

$$
\begin{array}{r}
u_{i}=\frac{v_{i}}{e+\|\mathrm{v}\|} \\
p_{i}=u_{i}+d t_{j i} \\
u_{i}=\frac{u_{i}+c p_{i}}{e+\|\mathrm{u}\|+c\|\mathrm{p}\|}
\end{array}
$$

Jika $\|r\|<p-e$, maka

$$
Y_{j}=-1(\text { Inhibit } \mathbf{J})
$$

Nilai reset $=$ true, ke langkah 5

Jika $\|r\|>p-e$, maka

$$
\begin{array}{r}
w_{i}=s_{i}+a u_{i} \\
x_{i}=\frac{w_{i}}{e+\|\mathrm{w}\|} \\
q_{i}=\frac{p_{i}}{e+\|\mathrm{p}\|} \\
v_{i}=f\left(x_{i}\right)+b f\left(q_{i}\right)
\end{array}
$$

Nilai reset $=$ false, ke langkah 8

8. Lakukan langkah 9-11 untuk jumlah iterasi

9. Modifikasi bobot untuk pemenang unit $J$.

$$
\begin{aligned}
t_{J i} & =\alpha d u_{i}+\{1+\alpha d(d-1)\} t_{J i} \\
b_{J i} & =\alpha d u_{i}+\{1+\alpha d(d-1)\} b_{J i}
\end{aligned}
$$

10. Modifikasi aktivasi $F 1$

$$
\begin{aligned}
u_{i} & =\frac{v_{i}}{e+\|v\|} \\
w_{i} & =s_{i}+\alpha u_{i} \\
p_{i} & =u_{i}+d t_{J i} \\
x_{i} & =\frac{w_{i}}{e+\|\mathrm{w}\|} \\
q_{i} & =\frac{p_{i}}{e+\|\mathrm{p}\|} \\
v_{i}=f\left(x_{i}\right) & +b f\left(q_{i}\right)
\end{aligned}
$$

11. Tes kondisi berhenti untuk tiap perubahan bobot

12. Tes kondisi berhenti untuk jumlah epoch yang telah ditentukan.

Fungsi aktivasi yang digunakan adalah

$$
f(x)= \begin{cases}x, & \text { if } x \geq \theta \\ 0, & \text { if } x<\theta\end{cases}
$$

\section{METODE}

Sebelum kinerja metode diukur, dilakukan pendefinisian tujuan pengujian, skenario pengujian dan parameter yang dibutuhkan dalam pengujian ini. Hasil pengujian dianalisis untuk menentukan pengaruh-pengaruh parameter pada masing-masing metode dan menentukan metode yang memiliki kinerja pengelompokan data yang lebih baik.

Pengujian yang dilakukan memiliki beberapa tujuan sebagai berikut:

1. Menganalisis pengaruh parameter learning rate, jumlah cluster, dan nilai neigborhood pada hasil cluster metode SOM.

2. Menganalisis pengaruh parameter vigilance factor, noise suppresion, dan bobot pada hasil cluster metode ART 2.

3. Menganalisis tingkat kesempurnaan hasil masing-masing metode berdasarkan indeks validasi Davies-Bouldin Index, Dunn Index, dan Silhouette Index.

Skenario pengujian dilakukan agar proses pengujian dapat mencapai tujuan yang diinginkan. Skenario pengujian yang dilakukan yaitu dengan melakukan proses clustering pada database yang sudah dipersiapkan. Untuk mengetahui

Anak Agung Gede Bagus Ariana: Perbandingan Metode SOM/Kohonen dengan ... p-ISSN:1693 - 2951; e-ISSN: 2503-2372

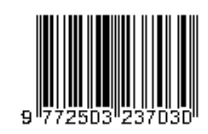


pengaruh masing-masing parameter, maka dilakukan pengujian terhadap kombinasi nilai parameter pada masingmasing metode. Adapun parameter yang akan diberi nilai kombinasi pada metode SOM dan ART 2 adalah sebagai berikut:

TABEL I

PARAMETER PENGUJIAN

\begin{tabular}{llll}
\hline Metode & Parameter & Simbol & Kombinasi Nilai \\
\hline SOM & Jumlah cluster & $\mathrm{nC}$ & $2,3,4,5$ \\
& Learning rate & $\alpha$ & 0,$2 ; 0,4 ; 0,6 ; 0,8 ; 0,9$ \\
& Neighborhood & $\mathrm{Ne}$ & $1,2,3,4,5$ \\
& value & & \\
\hline ART 2 & Vigilance factor & $\rho$ & 0,$7 ; 0,8 ; 0,9 ; 0,95$ \\
& Noise supression & $\theta$ & 0,$1 ; 0,2 ; 0,3 ; 0,4 ; 0,5$ \\
& Bobot & $\mathrm{w}$ & $1,2,3,4,5$ \\
\hline
\end{tabular}

Hasil cluster akan diuji dengan indeks validasi DaviesBouldin Index, Dunn Index, dan Silhouette Index. Parameter pembentuk cluster terbaik berdasarkan pengujian masingmasing indeks validasi akan disimulasikan pada proses pengenalan kelas masing-masing cluster.

\section{HASIL DAN PEMBAHASAN}

Berikut adalah proses segmentasi dengan menggunakan metode SOM dengan parameter jumlah cluster $=3$, learning rate $=0,9$, dan neighbor size $=2$.

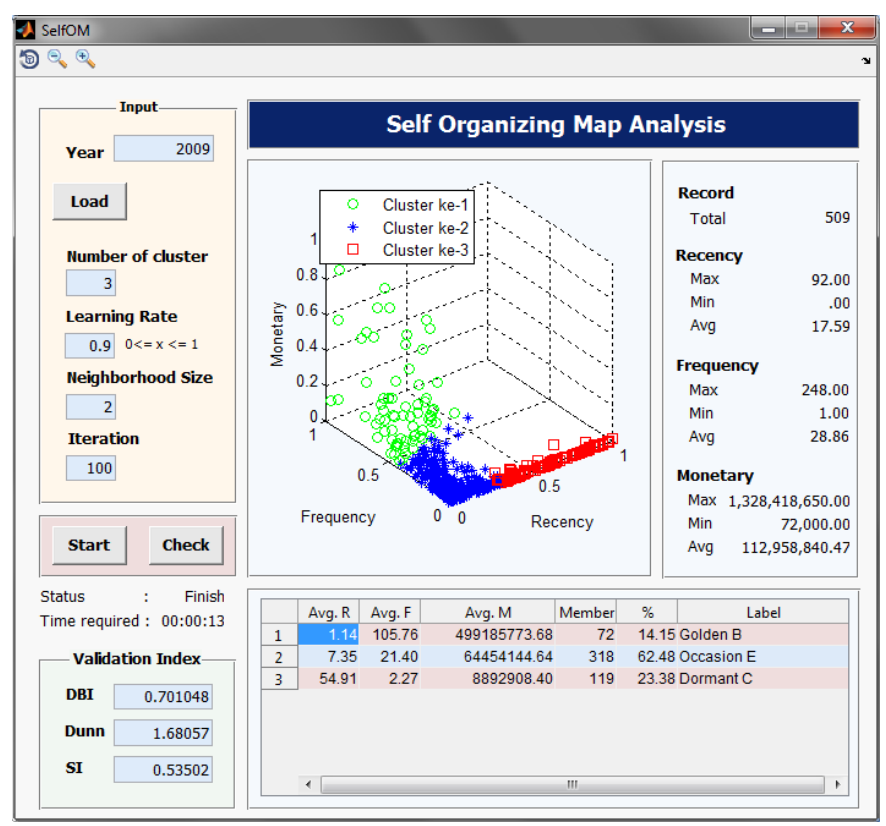

Gambar 3: Antar Muka Metode SOM/Kohonen

Berikut adalah ringkasan nilai indeks validasi cluster terbaik berdasarkan kombinasi nilai parameter pada metode SOM/Kohonen.
TABEL II

HASIL VALIDASI INDEX DATASET 2009 METODE SOM

\begin{tabular}{lrrlr}
\hline $\mathrm{nC}$ & $\alpha$ & $\mathrm{Ne}$ & Validasi & Nilai \\
\hline 4 & 0,$2 ; 0,8$ & 1,2 & Davies-Bouldin & 0,572172 \\
2 & $0,2 \mathrm{~s} / \mathrm{d} \mathrm{0,9}$ & $1 \mathrm{~s} / \mathrm{d} 5$ & Dunn Index & 2,457409 \\
3 & $0,2 \mathrm{~s} / \mathrm{d} \mathrm{0,9}$ & $1 \mathrm{~s} / \mathrm{d} 5$ & Silhouette Index & 0,53502 \\
\hline
\end{tabular}

Berdasarkan keseluruhan percobaan dapat disimpulkan sebagai berikut:

1. Nilai indeks validasi cluster sangat dipengaruhi oleh jumlah cluster.

2. Nilai neighbor satu dan dua menghasilkan nilai indeks validasi yang lebih baik.

3. Nilai learning rate tidak terlalu mempengaruhi nilai indeks validasi.

Berikut adalah proses segmentasi dengan menggunakan metode ART 2 dengan parameter vigilance factor $=0,9$; noise suppresion $=0,1$; dan bottom up weight $=1$.

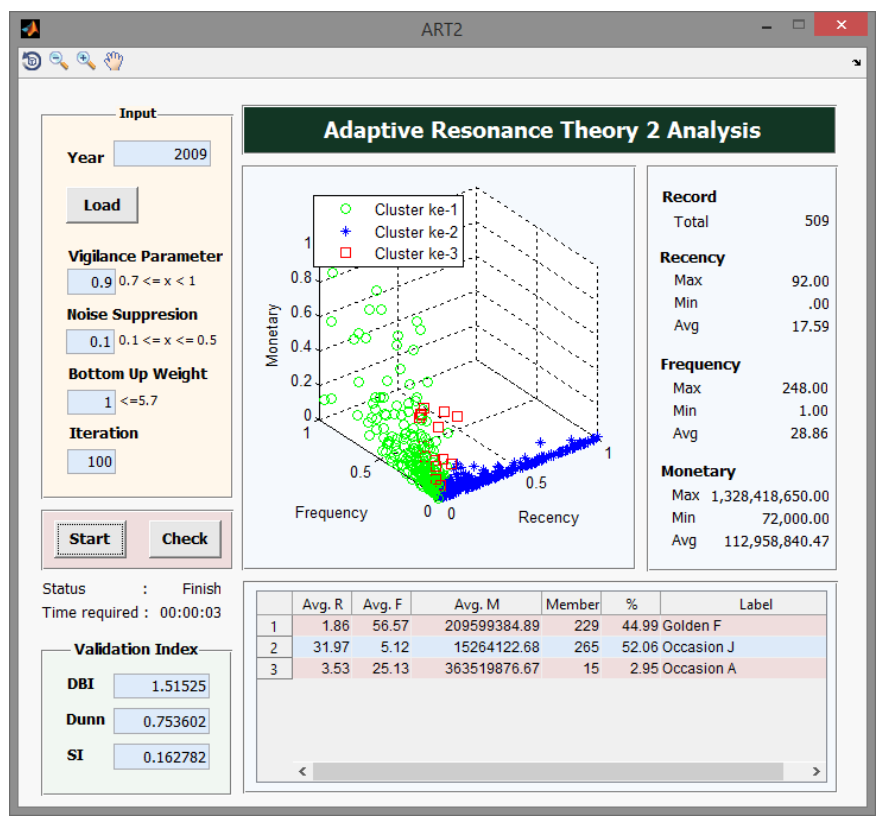

Gambar 4: Antar Muka Metode ART 2

Berikut adalah ringkasan nilai indeks validasi cluster terbaik berdasarkan kombinasi nilai parameter.

TABEL III

HASIL VALIDASI INDEX DATASET 2009 METODE ART 2

\begin{tabular}{lrrrlr}
\hline nC & $\rho$ & $\theta$ & w & Validasi & Nilai \\
\hline 2 & 0,$7 ; 0,8$ & 0,1 & 1 & $\begin{array}{l}\text { Davies-Bouldin } \\
\text { Index }\end{array}$ & 1,0893 \\
& 0,$7 ; 0,8$ & 0,1 & 1 & Dunn Index & 1,7959 \\
2 & 0,$7 ; 0,8$ & 0,1 & 1 & Silhouette Index & 0,3307 \\
\hline
\end{tabular}

Berdasarkan keseluruhan percobaan dapat disimpulkan sebagai berikut: 
Teknologi Elektro, Vol. 16, No. 02, Mei - Agustus 2017

1. Nilai vigilance factor atau derajat kewaspadaan sangat mempengaruhi jumlah cluster yang terbentuk. Semakin tinggi nilai vigilance factor maka semakin banyak cluster yang dihasilkan.

2. Nilai bobot juga mempengaruhi jumlah cluster yang dihasilkan. Semakin besar nilai bobot maka cluster yang terbentuk akan lebih banyak.

3. Nilai noise berpengaruh terhadap rata-rata nilai validasi cluster. Nilai noise yang kecil menimbulkan nilai validasi cluster yang lebih baik.

Nilai indeks validasi menunjukkan tingkat kesempurnaan cluster yang terbentuk. Berikut adalah ringkasan nilai validasi indeks.

TABEL IV

PERBANDINGAN NILAI VALIDASI METODE SOM DAN ART 2

\begin{tabular}{llcc}
\hline Indeks Validasi & Unjuk Kerja & SOM & ART 2 \\
\hline Davies-Bouldin & $\begin{array}{l}\text { Lebih rendah } \\
\text { semakin baik }\end{array}$ & $\mathbf{0 , 5 7 2 1 7 2}$ & 1,0893 \\
\hline Dunn & $\begin{array}{l}\text { Lebih tinggi } \\
\text { semakin baik }\end{array}$ & $\mathbf{2 , 4 5 7 4 0 9}$ & 1,7959 \\
\hline Silhouette & $\begin{array}{l}\text { Mendekati satu } \\
\text { semakin baik }\end{array}$ & $\mathbf{0 , 5 3 5 0 2}$ & 0,3307 \\
\hline
\end{tabular}

Tabel IV menunjukkan unjuk kerja metode SOM dinyatakan lebih baik daripada metode ART 2 diukur oleh validasi indeks Davies-Bouldin, indeks Dunn dan indeks Silhouette.

\section{KESIMPULAN}

Berdasarkan hasil penelitian, nilai Davies-Bouldin Index terendah, Dunn Index tertinggi dan Silhouette Index yang mendekati satu didapatkan dari metode SOM/Kohonen. Jadi Metode SOM/Kohonen menghasilkan pengelompokan cluster dengan lebih baik.

\section{REFERENSI}

[1] Tsiptsis, K., Chorianopoulos, A. (2009) Data Mining Techniques in CRM. United Kingdom: John Wiley and Sons

[2] Cheng, C. H. \& Chen Y. S. (2009) Classifying the segmentation of customer value via RFM model and RS Theory. Expert System with Application, 36, 4176-4184.

[3] Hughes, A. M. (1994) Strategic Database Marketing. Chicago: Probus Publishing Company.

[4] Nugraheni, Yohana (2013) Data Mining Using Fuzzy Method for Customer Relationship Management in Retail Industry. Lontar Komputer Vol. 4 No. 1, April 2013. ISSN: 2088-1541. Universitas Udayana.

[5] Smita, N., (2010) Potential use of Artificial Neural Network in Data Mining. Computer and Automation Engineering (ICCAE), 2010 The 2nd International Conference. Vol.2, 339-343.

[6] Ariana, A.A. Gede Bagus (2011) Customer Segmentation dengan Metode Self Organizing Map (Studi Kasus: UD. Fenny) Lontar Komputer Vol. 2 No. 1 Juni 2011. ISSN: 2088-1541. Universitas Udayana

[7] Ariana, A.A. Gede Bagus., Dita Andriawan, I Wayan (2014) Segmentasi Pelanggan PDAM dengan Metode Adaptive Resonance Theory 2. Prosiding Seminar Nasional Ilmu Komputer 2014. ISBN: 978-602-19406-2-4. Universitas Gadjah Mada Yogyakarta.

[8] Kohonen, T. (1990) The Self-Organizing Map, Invited Paper. Procedings of the IEEE, Vol. 78, No. 9, September 1990.
[9] Carpenter, G.A., \& S. Grossberg (1987) ART 2: Self-organization of Stable Category Recognition Codes for Analog Input Patterns. Applied Optics. 26:4919-4930. A reprint from Applied Optics volume 26, number 23, December 1987.

[10] Yao, X. (1999) Evolving Artificial Neural Networks, Proceedings of the IEEE, 7(9):1423-1447, September 1999.

[11] Sivanandam, S. N., Sumathi, S. (2006) Introduction to Data Mining and its Applications. Spinger, Verlag Berlin Heidelberg.

[12] Sivanandam, S. N., Sumathi, S., \& Deepa, S. N. (2006) Introduction to neural networks using MATLAB 6.0. New Delhi: The McGraw-Hill Companies.

[13] Fausset, Laurene (1994) Fundamentals of Neural Networks: Architectures, Algorithms and Applications. Prentice-Hall, New Jersey, USA.

Anak Agung Gede Bagus Ariana: Perbandingan Metode SOM/Kohonen dengan ... p-ISSN:1693 - 2951; e-ISSN: $2503-2372$

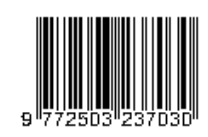

